Virial coeffici ent s of met hane, et hane, and thei $r$ mixtures at I ow temper at ures

\begin{tabular}{|l|l|}
\hline 著者 & $\begin{array}{l}\text { Hoover Al an E., Nagat a I sam, Lel and Jr. } \\
\text { Thomas W, Kobayashi Ri ki }\end{array}$ \\
\hline 著者別表示 & 長田 勇 \\
\hline $\begin{array}{l}\text { j ournal or } \\
\text { publ i cat i on titl e }\end{array}$ & The Journal of Chem cal Physi cs \\
\hline vol une & 48 \\
\hline number & 6 \\
\hline page r ange & 2633 2647 \\
\hline year & 1968 \\
\hline URL & ht t p: //doi . or g/10.24517/00049724 \\
\hline
\end{tabular}




\title{
Virial Coefficients of Methane, Ethane, and Their Mixtures at Low Temperatures
}

\author{
alan E. Hoover, ${ }^{*}$ I. Nagata, $†$ Thomas W. Leland, Jr., and Riki Kobayashi \\ William Marsh Rice Universily, Housion, Texas \\ (Received 17 February 1967)
}

\begin{abstract}
A Burnett apparatus designed specifically for the measurement of virial coefficients was constructed and used to establish the second and some third virial coefficients of methane, ethane, and five equally spaced compositions at $273.15^{\circ}, 240.00^{\circ}$, and $215.00^{\circ} \mathrm{K}$. Second and third virial coefficients for methane were also determined at $200^{\circ}, 191.06^{\circ}$, and $131.93^{\circ} \mathrm{K}$. By using a gas-lubricated dead-weight gage located in a vacuum of approximately $25 \mu \mathrm{Hg}$, absolute pressures could be read directly. The gage located in an ambient vacuum also allowed the determination of accurate compressibility factors from $40 \mathrm{~atm}$ down to the neighborhood of one atmosphere pressure. A recently developed method for the determination of virial coefficients directly from Burnett pressure measurements was applied. The range of the experimental apparatus enabled the determination of several negative values of the third virial coefficients at low reduced temperatures along with positive values at the higher temperatures. The experimental second and third virial coefficients of this and past studies were used to determine the Kihara, Lennard-Jones, and square well potential parameters. The accuracy of the representation of the virial data by the parameters over a wide range of temperatures is given.
\end{abstract}

\section{INTRODUCTION}

Serious efforts have been made to develop various methods for the measurement of virial coefficients of gases. Methods recently used to-determine virial coefficients are as follows:

(1) the application of the principle of gas thermometry, ${ }^{1}$

(2) the comparison of volumetric behavior of one gas with another, ${ }^{2}$

(3) the measurement of Joule-Thompson coeffcients, ${ }^{3-6}$

(4) the use of fixed-volume-variable-mass methods, ${ }^{7-9}$ and

(5) the Burnett expansion sequence ${ }^{10}$ along with various procedures of evaluating the coefficients. ${ }^{11-14}$

This work uses the method in item(5) and discusses

*Present address: E. I. du Pont de Nemours Co., Wilmington, Del.

$\dagger$ Present address: Dept. of Chemical Engineering, University of Kanazawa, Kanazawa, Japan.

1 E. O. Price, Ph.D. thesis, Ohio State University, Columbus, Ohio, 1938.

${ }^{2}$ G. Thomaes and R. R. van Steenwinkel, Nature 187, 229 $(1960)$.

${ }^{2}$ E. Kanda, Sci. Repts. Res. Inst. Tohoku Univ. Ser. A 1, 157 (1949)

A. Eucken and A. Parks, Z. Physik. Chem. B20, 184 (1933).

${ }^{5} \mathrm{E}$. C. Kerr, Ph.D. thesis, Ohio State University, Columbus, Ohio, 1957.

6 J. R. Roebuck, Phys. Rev. 2, 301 (1913).

7 J. A. Beattie, Proc. Am. Acad. Arts Sci. 69, 389 (1934).

A. Michels, W. DeGraaft, T. Wassenaar, J. M. H. Levelt, and P. Louwerse, Physica 25, 25 (1959).

${ }^{2}$ D. R. Douslin, Progr. Intern. Res. Thermodyn. Transport Properties Symp. 2nd Princeton Univ., Princeton, N.J., p. 135, (1962).

${ }^{10}$ E. S. Burnett, J. Appl. Mech. 58, A136 (1936).

"F. B. Canfield, T. W. Leland, and R. Kobayashi, Advan. Cryog. Eng. 8, 146 (1963).

I. Hoover, F. B. Canfield, R. Kobayashi, and T. W. Leland, Jr., J. Chem. Eng. Data 9, 568 (1964).

ia R. E. Barieau and B. J. Dalton, U.S. Bur. Mines

${ }^{14}$ G. M. Kramer and J. G. Miller, J. Phys. Chep. 61, 785 (1957).

$$
\text { Rept of Inv. 7020. September pp } 3 \ddot{4}(1967)
$$

some of its advantages for the determination of second and third virial coefficients. The authors have discussed in an earlier paper ${ }^{11}$ the use of this method for PVT measurements, and it was adopted for use in this work. Recently, Crain and Sonntag ${ }^{15}$ measured the compressibilities of argon, nitrogen, and three mixtures of argon and nitrogen down to temperatures as low as $143^{\circ} \mathrm{K}$. They derived both second and third virial coefficients from the compressibility data. Many others have applied the Burnett method to obtain PVT data at higher temperatures from which virial coefficients have been derived. ${ }^{14,16-21}$

A review of the existing data indicated that the measured second virial coefficients for methane from several sources were in substantial agreement above $230^{\circ} \mathrm{K} \cdot{ }^{1,2,22-29}$ Also the second virial coefficients for

${ }^{15}$ R. W. Crain, Jr., and R. E. Sonntag, Advan. Cryog. Eng. 11, 379 (1965).

${ }^{18}$ R. C. Harper, Jr., and S. G. Miller, J. Chem. Phys. 27, 36 (1957).

${ }^{27}$ W. C. Pfefferle, Jr., J. A. Goff, and J. G. Miller, J. Chem. Phys. 23, 509 (1955)

${ }_{18}$ W. G. Schneider, Can. J. Res. B27, 339 (1949).

19 W. G. Schneider and J. A. H. Duffie, J. Chem. Phys. 17, 751 (1949).

${ }_{20}$ I. H. Silberberg, J. J. McKetta, and K. A. Kobe, J. Chem. Eng. Data 4,314 (1959)

${ }^{21} \mathrm{~J}$. L. Yntema and W. G. Schneider, J. Chem. Phys. 18, 641 $(1950)$.

J. A. Beattie and W. H. Stockmayer, J. Chem. Phys. 10, 473 (1942).

${ }^{23}$ D. R. Douslin, Progr. Intern. Res. Thermodyn. Transport Properties Symp., 2nd, Princeton Univ., Princeton, N.J., 135 (1962).

${ }_{24}$ D. R. Douslin, R. H. Harrison, R. T. Moore, and J. P. McCullough, J. Chem. Eng. Data 9, 358 (1964).

${ }^{25} \mathrm{H}$. W. Schamp, E. A. Mason, A. C. B. Richardson, and A. Altman, Phys. Fluids 1, 329 (1958).

${ }_{26}$ H. M. Kvalnes and V. L. Gaddy, J. Am. Chem. Soc. 53, 394 (1931).

${ }^{27}$ A. Michels and D. W. Nederbragt, Physica's Grav. 3, 569 (1936).

${ }^{28} \mathrm{~W}$. H. Mueller, Ph.D. thesis, Rice University, Houston, Tex., 1959.

${ }_{29}$ W. H. Mueller, T. W. Leland, and R. Kobayashi, A. I. Ch. E. J. 7, 267 (1961). 


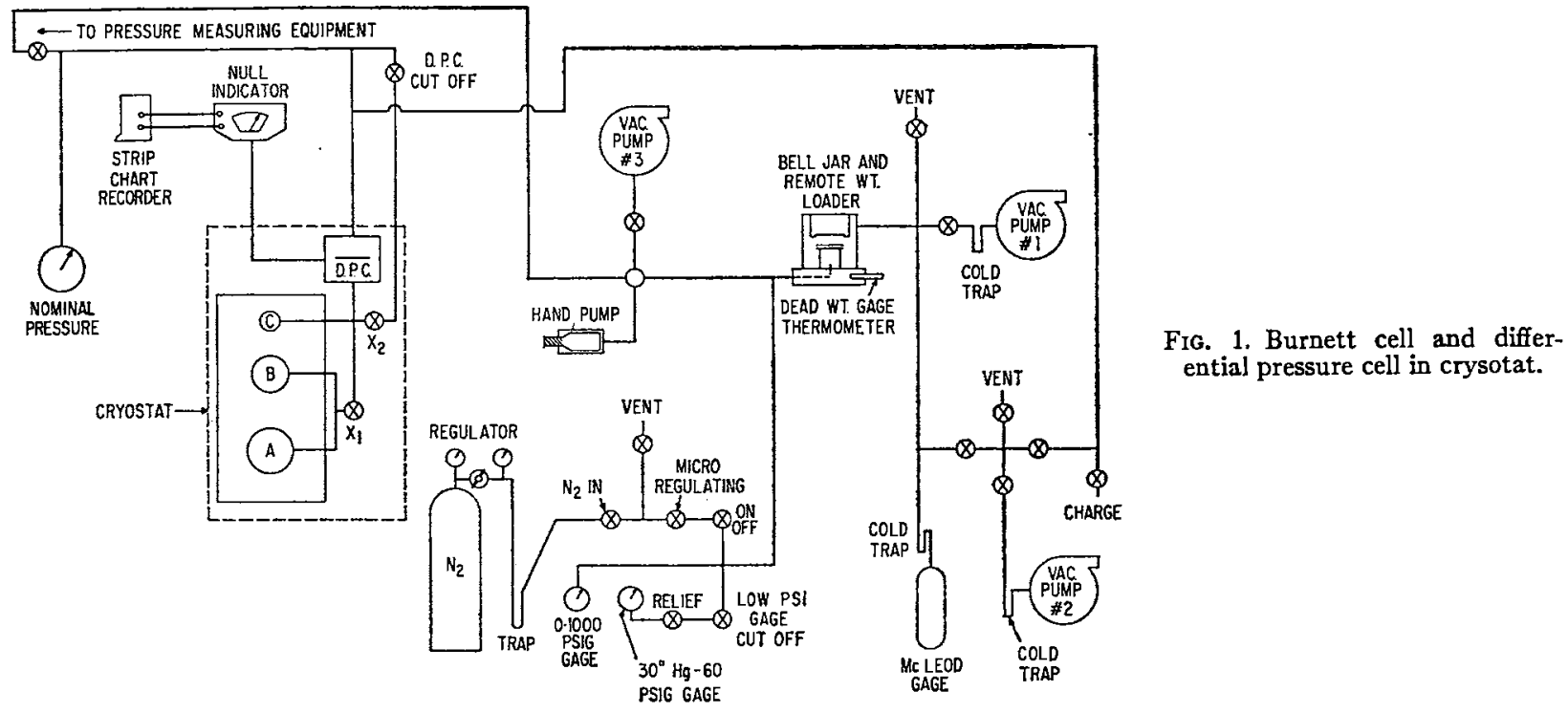

methane appear to be reasonably represented by two corresponding states correlations. ${ }^{30,31}$ The experimental second virial coefficients for methane below $230^{\circ} \mathrm{K}$ which have been contributed from four sources: Price, ${ }^{1}$ Mueller et al., ${ }^{29} \mathrm{Kanda}^{3}$ and Thomaes and van Steenwinkel, ${ }^{2}$ appear to be in serious disagreement. One of the objectives of this study was a redetermination of the second virial coefficient for methane at low temperatures to substantiate both the validity of the general correlations and the previously reported experimental values.

The second virial coefficients for ethane has also been reported previously $y^{4,32-34}$ and correlated with the corresponding states method cited above. Serious lisagreements in the virial coefficients from the various

TABLE I. Gases studied.

\begin{tabular}{lcc}
\hline Gas & $\begin{array}{r}\text { Mole \% } \\
\text { methane }\end{array}$ & $\begin{array}{c}\text { Mole \% } \\
\text { ethane }\end{array}$ \\
\hline Methane & 100.0 & $\ldots$ \\
Mixture A & 20.10 & 79.90 \\
Mixture B & 35.38 & 64.62 \\
Mixture C & 51.44 & 48.56 \\
Mixture D & 68.27 & 31.73 \\
Mixture E & 83.43 & 16.57 \\
Ethane & $\cdots$ & 100.00 \\
\hline
\end{tabular}

${ }^{20}$ M. L. McGlashan and D. L. B. Potter, Proc. Roy. Soc. (London) A267, 478 (1962).

${ }^{31} \mathrm{~K}$. S. Pitzer and R. F. Curl, J. Am. Chem. Soc. 79, 2369 (1957)

${ }_{32}$ J. A. Beattie, C. Hadlock, and N. Poffenberger, J. Chem. Phys. 3, 93 (1935)

${ }^{33}$ S. D. Hamann and W. J. McManamey, Trans. Faraday Soc. 49, 149 (1953).

${ }^{34}$ A. Michels, W. van Straaten, and J. Dawson, Physica 20, 17 (1954). sources exist at all temperatures, but the disagreement among the experimental data and the discrepancy between the experimental data and the correlations of McGlashan and Potter, ${ }^{30}$ and Pitzer and Curl ${ }^{81}$ appear to increase with decreasing temperatures. Consequently, in this study renewed experimental efforts have been directed toward the measurement of ethane second virial coefficients at low temperature. For the two gases under consideration the third virial coefficients have been measured in the neighborhood of $T_{R}=1.0$ and greater. The general problem of the accurate measurement of the third virial coefficients for any substance at lower reduced temperatures remains difficult. Efforts directed towards the development and applications of an apparatus capable of measuring the third virial coefficients at low reduced temperatures are needed.

There are no known values for the interaction second or third virial coefficients for methane-ethane mixtures and any contribution of such data would add materially to the formal study of gas mixtures.

\section{EXPERIMENTAL APPARATUS}

Experimental Burnett apparatus for low-temperature application has been described previously. ${ }^{29}$ However, for the ensuing discussion and because of several special features incorporated in the present apparatus, a simplified flow diagram of the apparatus is presented in Fig. 1. Since in a Burnett sequence of expansions ${ }^{10}$ only pressure and temperature measurements need to be made, considerations regarding their measurement and control are crucial in the apparatus design.

A comparison of the present and previous low-temperature Burnett apparatus ${ }^{29}$ indicates the following revised features:

(1) a three-chambered pressure cell with spherical 
chambers allowing greater flexibility in the selection of the cell volume ratios (up to 12),

(2) an enclosed gas dead-weight gage (DWG) operating on nitrogen in an ambient pressure of about $25 \mu \mathrm{Hg}$ allowing direct measurement of absolute pressures,

(3) a diaphragm-differential-pressure cell (DPC) operating on the linear-differential-transformer principle permitting isolation of the fluid investigated from the nitrogen gas while sensitively transmitting pressure between them, and

(4) a bridge circuit monitoring temperatures with sensitivity to $\pm 0.0005^{\circ} \mathrm{C}$.

In addition a two-stage cascade refrigeration system was constructed to supply constant-load long-period refrigeration in the temperature range between $32^{\circ}$ and $-116^{\circ} \mathrm{F}$. Details of these and other experimental features of the apparatus are described by Hoover. ${ }^{35}$

Although the bulk of the apparatus was designed for for an upper operating pressure of $500 \mathrm{~atm}$, the upper pressure limit of $40 \mathrm{~atm}$ was placed upon this work by the limitation of the dead-weight gage. The lower temperature limit on the study of various gases is determined by a combination of factors such as the cell constant, the vapor pressure of the substance under study, the closeness of the compressibility factors to unity, and the lowest pressures which can be measured accurately. The interrelationship of these factors will be discussed further in the section on error analysis.

TABIE II. A comparison of the values of virial coefficients obtained in this work with similar values obtained by other investigators.

\begin{tabular}{|c|c|c|c|}
\hline Investigator & $\underset{(\mathrm{cc} / \mathrm{mole})}{\mathrm{B}}$ & $\frac{\mathrm{C}}{(\mathrm{cc} / \mathrm{mole})^{2}}$ & $\begin{array}{c}\text { Ref. } \\
\text { no. }\end{array}$ \\
\hline \multicolumn{4}{|c|}{ For methane at $273.15^{\circ} \mathrm{K}$} \\
\hline This work & -53.28 & 2669 & $\ldots$ \\
\hline This work ${ }^{a}$ & -53.36 & & ... \\
\hline Douslin & -53.35 & 2620 & 9 \\
\hline Michels & -53.66 & & 27 \\
\hline Michelsb & -53.43 & & 27 \\
\hline Schamp & -53.33 & & 25 \\
\hline Kvalnes & -54.06 & & 26 \\
\hline $\begin{array}{l}\text { Saville } \\
\text { Prill }\end{array}$ & -53.40 & & 39 \\
\hline Price $273.1^{\circ} \mathrm{K}$ & $\begin{array}{l}-34.4,-31.9,-36.5 \\
-34.1,-32.9,-35.7\end{array}$ & & 1 \\
\hline Price & -34.3 (average of six) & & 1 \\
\hline $\begin{array}{l}\text { McGlashan- } \\
\text { Potter Eq. }\end{array}$ & -52.25 & & 30 \\
\hline Pitzer-Curl Eq. & -53.96 & & 31 \\
\hline \multicolumn{4}{|c|}{ For ethane at $273.15^{\circ} \mathrm{K}^{\mathrm{d}}$} \\
\hline $\begin{array}{l}\text { This work } \\
\text { Michels }\end{array}$ & $\begin{array}{l}-223.41 \\
-221.45\end{array}$ & $\begin{array}{ll}11372 \\
10607\end{array}$ & $\ddot{34}$ \\
\hline
\end{tabular}

Value $=-53.28$ was corrected for $0.03 \% \mathrm{CO}_{2}, 0.2 \% \mathrm{~N}$.

${ }^{b}$ Value $=-53.66$ was corrected for $0.2 \% \mathrm{C}_{2} \mathrm{H}_{6}$. Value of $\mathrm{BCH}_{1}-\mathrm{C}_{2} \mathrm{H}_{6}$ from this work, Table VII was used.

'Saville's judgment after evaluation of data of Refs. 25-27.

d $0^{\circ} \mathrm{C}=273.15^{\circ} \mathrm{K}$ in this work.

as A. E. Hoover, Ph.D. thesis, Rice University, Houston, Tex.

1965. Available from University Microfilms, Ann Árbor, Michigan.

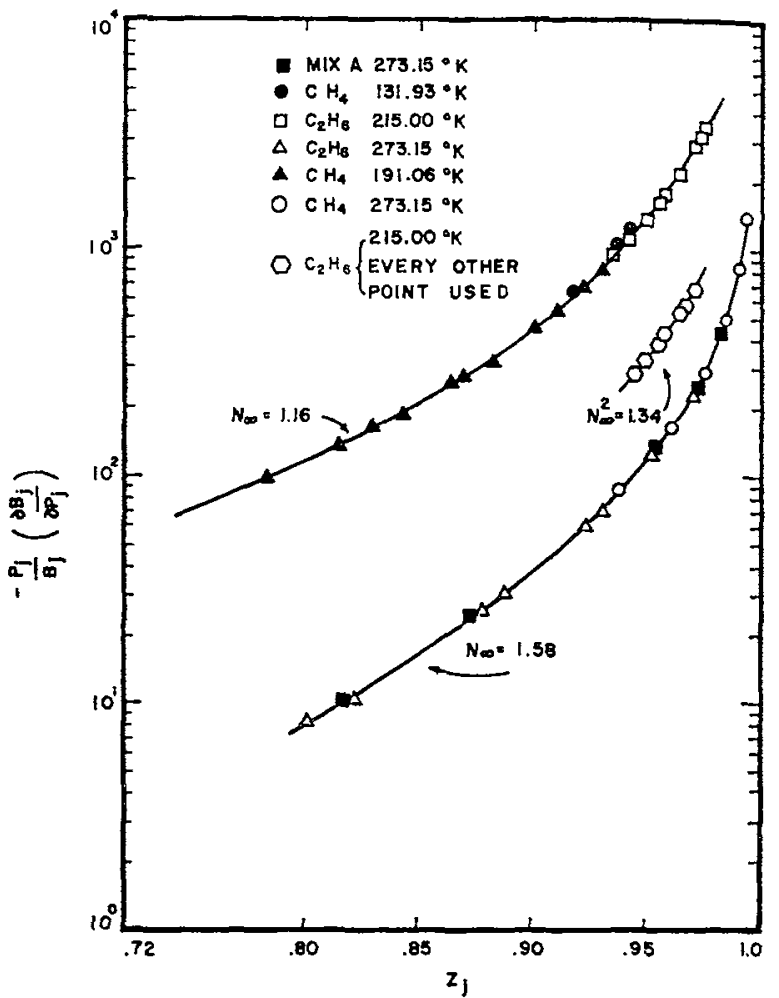

FIG. 2. Dimensionless relative error in second virial coefficients due to small errors in experimental pressures versus compressibility.

\section{BASIC MEASUREMENTS TAKEN DURING BURNETT EXPANSIONS}

The sequence of expansions required in the Burnett method has been discussed previously..$^{10}$ The analytical relations for the method indicate that pressure is the primary measurement for a run conducted under isothermal conditions.

In general, a pressure measurement using a liquid dead-weight gage requires:

(1) corrections due to weight bouyancy,

(2) corrections due to differences in the operating and calibration temperature,

(3) corrections due to the distortion of the piston area with pressure,

(4) corrections due to the hydraulic head of the confining fluid between the DPC and the gage,

(5) corrections due to zero shift of the DPC with pressure and temperature, and

(6) corrections to convert ambient to absolute pressures.

By recourse to a gas-lubricated, dead-weight gage placed in a constant ambient gas pressure of about $25 \mu \mathrm{Hg}$ it was possible to eliminate corrections (1), (4), and (6). Due to the moderate pressure application, correction (3) was found to be negligible. 


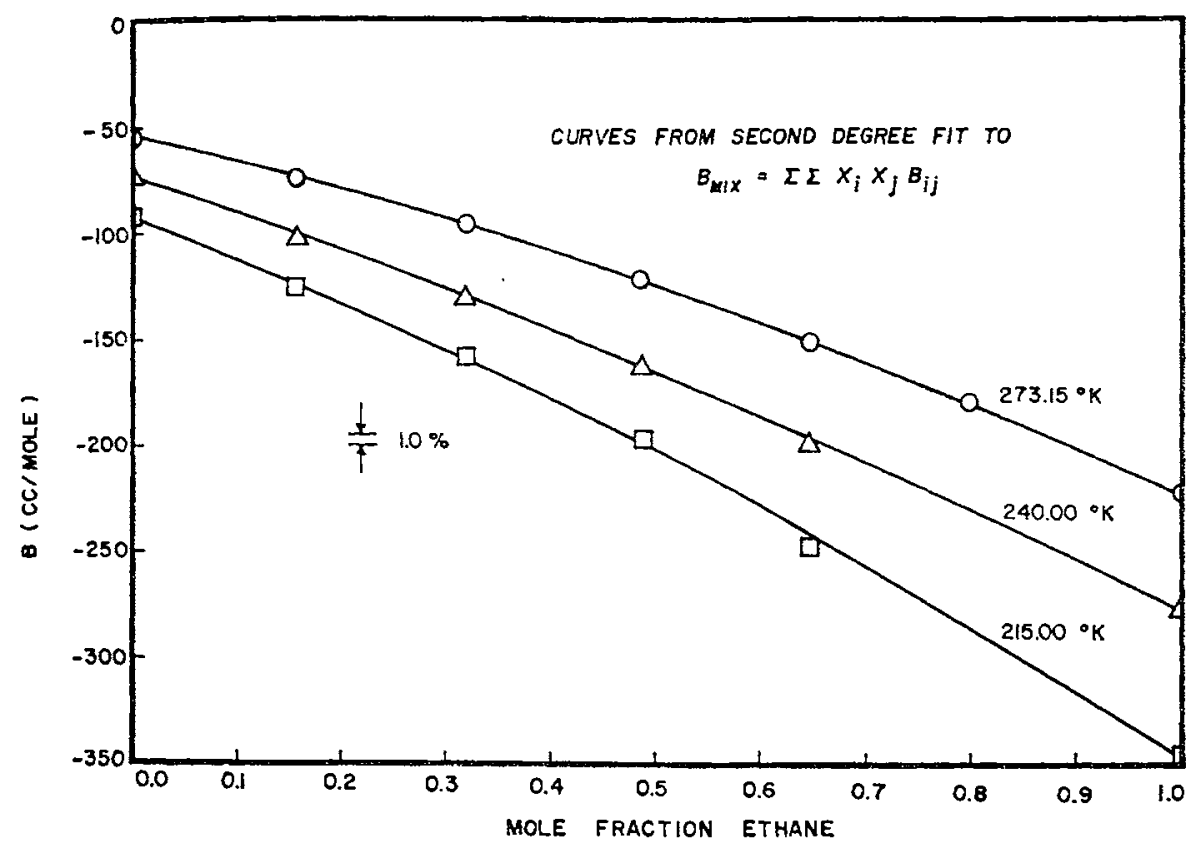

FIG. 3. Experimental second virial coefficients along isotherms.

Controlled temperature applications also caused correction (2) to be negligible since it is estimated to be two parts in $10^{6}$ of the pressure measured per $0.1^{\circ} \mathrm{C}$ change of the piston temperature. The only remaining correction, item (5), was determined by measuring any DPC zero shift after each pressure measurement.

The primary errors contributing to the pressure measurements are:

(1) lack of knowledge of precise piston area $( \pm 0.01 \%)$, and

(2) uncertainties in the mass of the weights $( \pm 0.0005 \%)$.

The temperature was controlled to $\pm .0005^{\circ} \mathrm{C}$ with probable knowledge of the absolute temperature to $\pm 0.01^{\circ} \mathrm{C}$ based on the platinum resistance temperature calibration and readings.
It has been noted that the resolution of the deadweight gage is intimately related to the temperature regulation of the cryostat. With temperature regulation to $\pm 0.0005^{\circ} \mathrm{C}$ a pressure resolution of as high as \pm 1 parts in 600000 was obtained near the upper pressure limit of the DWG.

The details of the operational procedure and the primary readings taken are reported elsewhere..$^{35}$

\section{MATERIALS INVESTIGATED}

The gases studied in this investigation were methane, ethane, and five mixtures of the two.

The research grade ethane was donated by the Phillips Petroleum Company with a reported purity of 99.99 mole $\%$ as determined by mass spectrometer analysis. The principle impurity was stated to be ethylene. No further purification of the ethane was

TABLF III. Values of the experimental second virial coefficients for methane, ethane, and five mixtures in cc/mole and their maximum probable errors (MPE).a

\begin{tabular}{|c|c|c|c|c|c|c|}
\hline Gas & $273.15^{\circ} \mathrm{K}$ & MPE & $240.00^{\circ} \mathrm{K}$ & MPE & $215.00^{\circ} \mathrm{K}$ & MPE \\
\hline $\begin{array}{l}\text { Methane } \\
\text { Mixture E } \\
\text { Mixture D } \\
\text { Mixture C } \\
\text { Mixture B } \\
\text { Mixture A } \\
\text { Ethane }\end{array}$ & $\begin{array}{r}-53.28 \\
-74.54 \\
-95.91 \\
-122.82 \\
-151.01 \\
-180.07 \\
-223.41 \\
\sigma^{c}=0.29\end{array}$ & $\begin{array}{l}0.2 \% \\
0.6 \% \\
0.4 \% \\
0.2 \% \\
0.3 \% \\
0.5 \% \\
0.1 \%\end{array}$ & $\begin{array}{c}-72.72 \\
-102.9 \mathrm{~b} \\
-130.0 \\
-162.20 \\
-198.36 \\
\ldots . . \\
-276.5 \\
\sigma=0.96\end{array}$ & $\begin{array}{l}0.3 \% \\
0.8 \% \\
0.6 \% \\
0.8 \% \\
0.7 \% \\
0.4 \%\end{array}$ & $\begin{array}{l}-92.59 \\
-125.6 \\
-158.6^{b} \\
-197.43^{b} \\
-247.65^{b} \\
\cdots \\
-340.63^{b} \\
\sigma=3.1\end{array}$ & $\begin{array}{l}0.4 \% \\
0.6 \% \\
0.6 \% \\
1.0 \% \\
4.0 \% \\
1.0 \%\end{array}$ \\
\hline Gas & $200.00\left({ }^{\circ} \mathrm{K}\right)$ & MPE & $191.06\left({ }^{\circ} \mathrm{K}\right)$ & MPE & $131.93\left({ }^{\circ} \mathrm{K}\right)$ & MPE \\
\hline Methane & -106.12 & $1.0 \%$ & -116.31 & $1.0 \%$ & $-224^{b}$ & $9.0 \%$ \\
\hline
\end{tabular}

MPE =errors in gas analysis $+\Sigma$ calculated errors in experimental measurements.

b These six values were calculated by using the apparatus constant 
FiG. 4. Summary of experimental second virial coefficients at constant composition taken in this work.

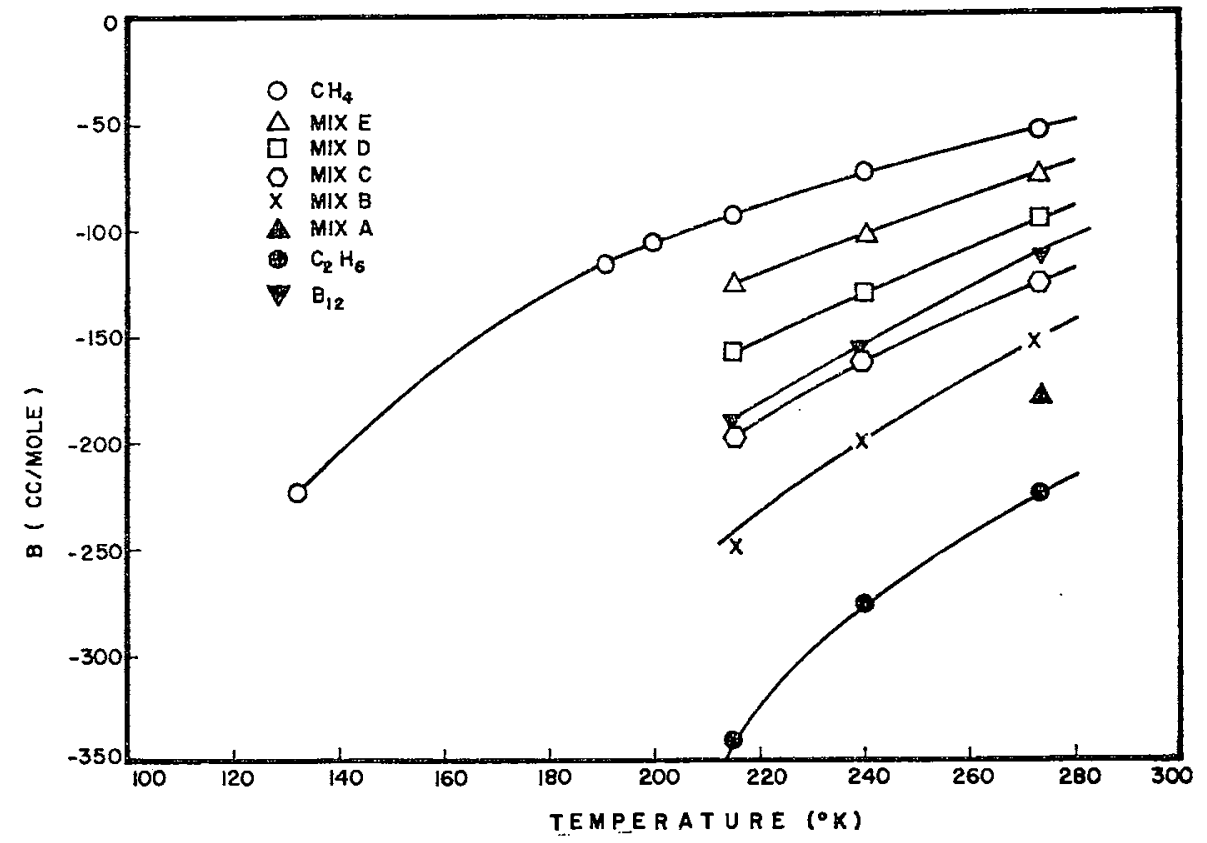

performed after it was determined that the reported analysis was correct by two other independent massspectrometer analyses.

The methane gas was obtained from the North Louise Gas Field from the Tennessee Gas Transmission and the Associated Oil and Gas Companies. The methane was partially purified by passing it through silica gel at the well head. For the methane studies it was further purified by passing through an adsorbent train to remove the traces of carbon dioxide and ethane not removed from the gas in the preliminary purification process.

The methane-ethane mixtures were made up from the research grade ethane and the methane as received. As a result traces of carbon dioxide and nitrogen were present in the final gas mixtures. The detailed analysis of the mixture compositions are reported elsewhere. ${ }^{35}$ An error analysis showed that the small concentrations of carbon dioxide and nitrogen (up to a few tenths of $1 \%$ ) could be reassigned as methane without sig-
FIG. 5. Comparison of methane second virial coefficients of this work and literature.

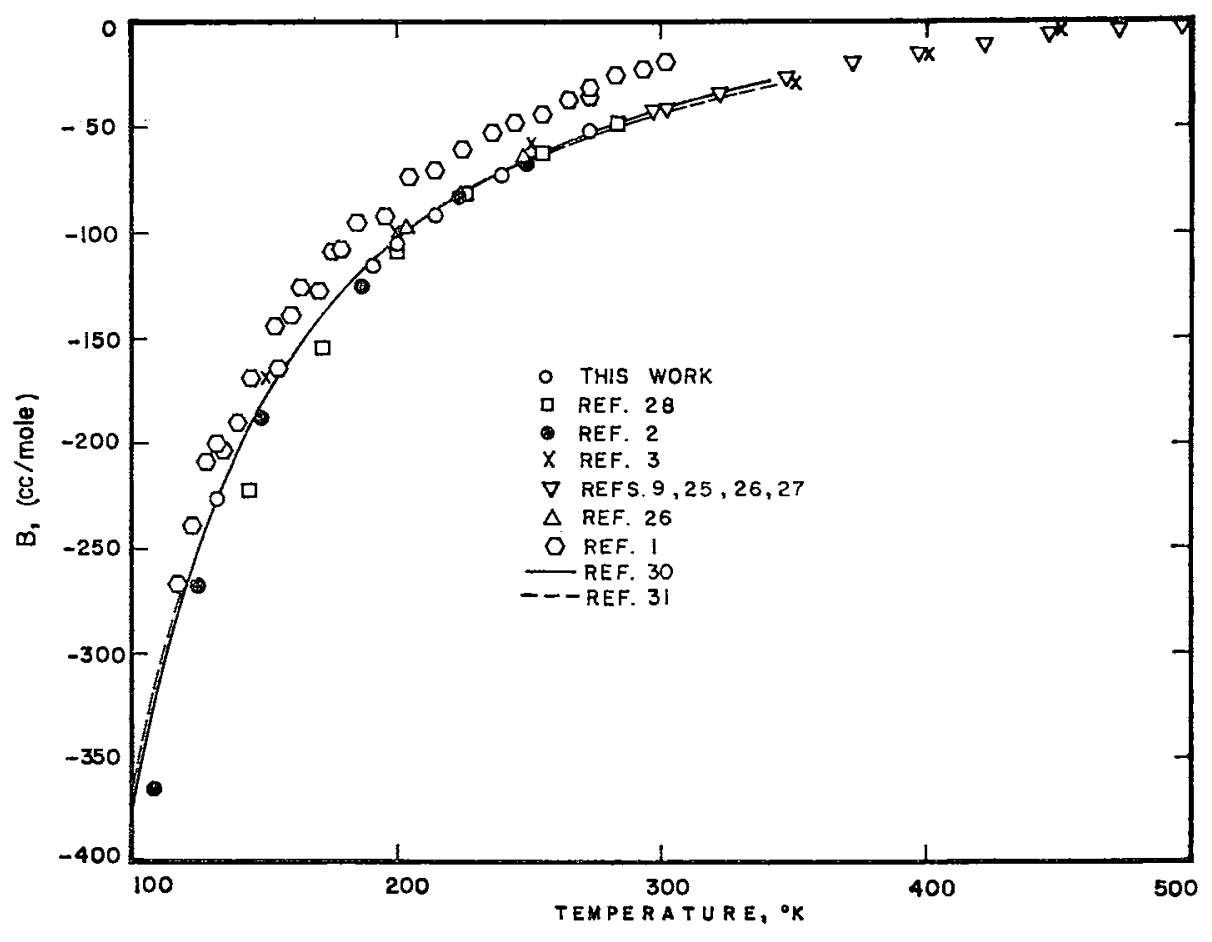




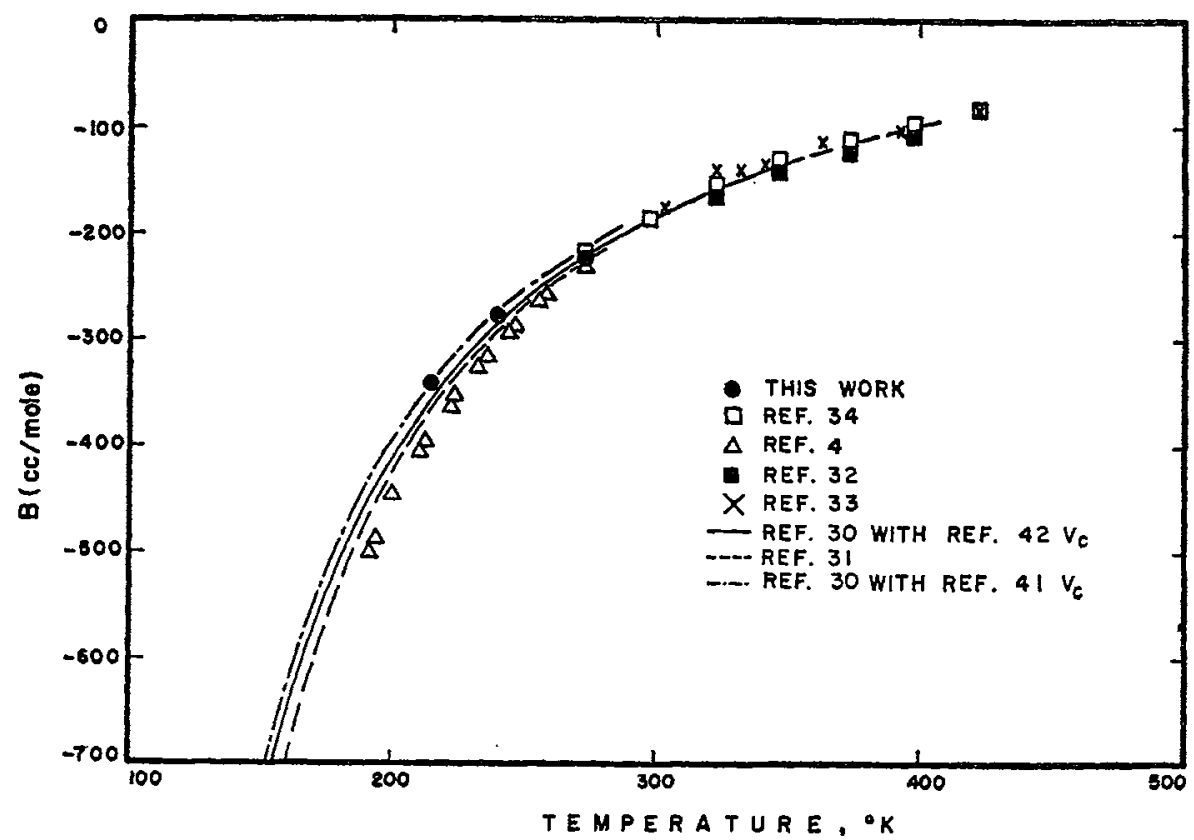

FIG. 6. Comparison of ethane second virial coefficients of this work and literature. nificantly affecting the errors in the calculated virial coefficients. At $273.15^{\circ} \mathrm{K}$ there were a sufficiently large number of experimental runs to evaluate this small concentration error (see Table II).

The gas composition based on three independent mass-spectrometric analyses which were used in the computations carried out in this work are listed in Table I.

\section{CALCULATION METHODS}

Two different methods were used to reduce the basic data to second and third virial coefficients and/or compressibility factors. First, the "apparatus constant" method, as modified by Canfield et al., II was employed at 215.00 and $240.00^{\circ} \mathrm{K}$. This method requires a calibration to determine the apparatus constant $N_{\infty}$ which measures the volume ratios of the chambers in the Burnett equipment. At these temperatures methane was used as the calibrating gas rather than helium as used by Canfield. At $131.93^{\circ} \mathrm{K}$ a single helium calibration run was made. This method determines conpressibility factors from the Burnett expansion in the usual manner. Virial coefficients are then calculated from the limiting behavior of the relation between

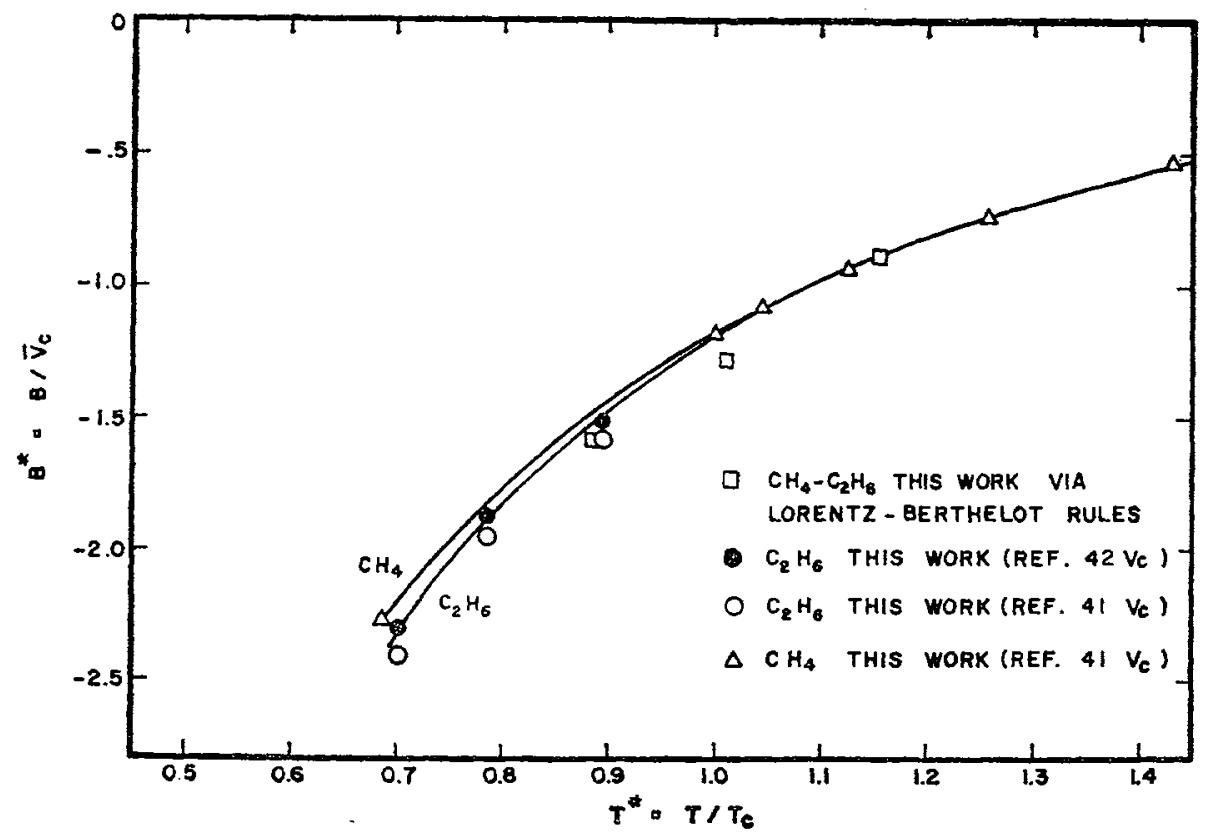

F1G. 7. Reduced second virial coefficients. 


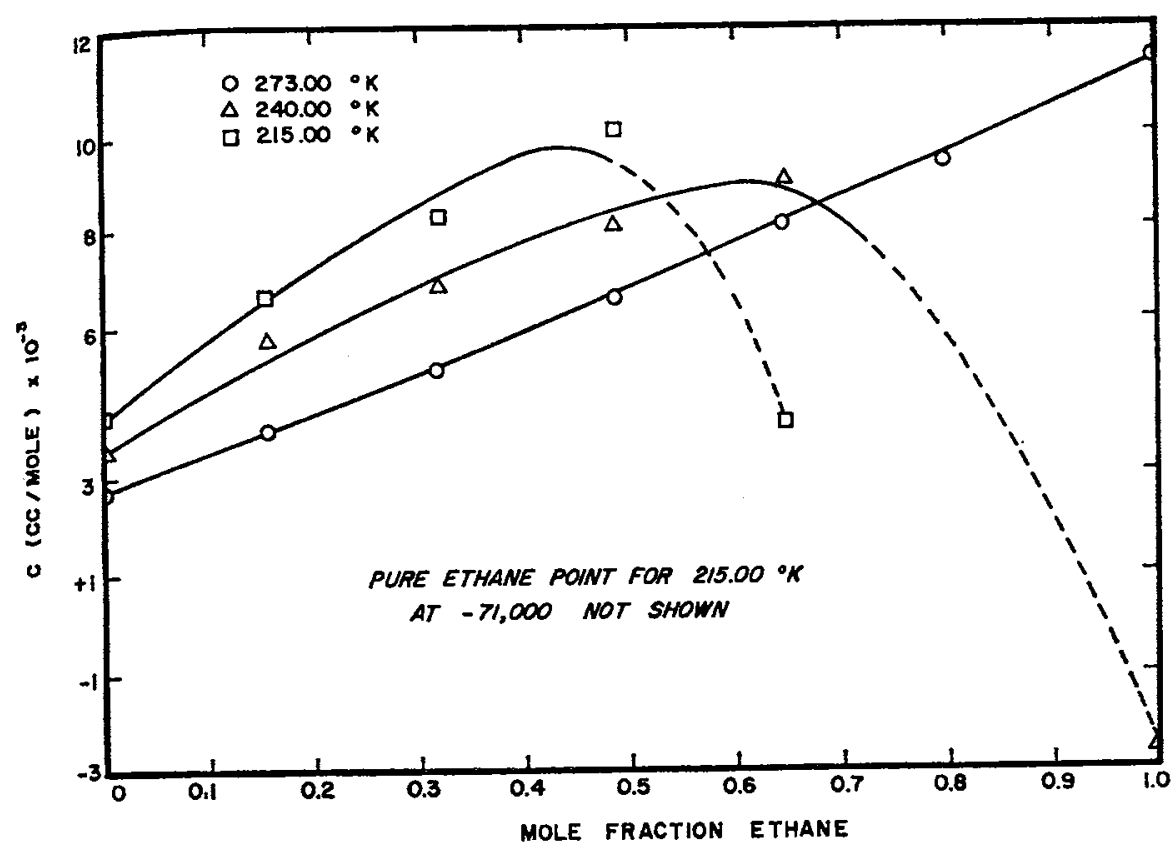

Fig. 8. Graphical summary of experimental third virial coeffcients along isotherms.

these compressibility factors and density at low pressures.

The second method used was called the "direct" method and was used at $191.06^{\circ}, 200.00^{\circ}$, and $273.15^{\circ} \mathrm{K}$. It does not require a calibration experiment to determine the cell constant. Starting with the Burnett expression relating the pressure of the $j$ th expansion, $P_{j}$, to the compressibility factor, $Z$, and the pressure for the $(j-1)$ th and the $(j+1)$ th expansion, one obtains ${ }^{12}$ :

$$
\left(P_{j} / Z_{j}\right)^{2}-\left(P_{j-1} P_{j+1}\right) /\left(Z_{j+1} Z_{j-1}\right)=0 .
$$

It has been determined ${ }^{36}$ that the assumption equal successive values of the cell constant introduces negligible errors. Consequently:

$$
N_{j}=N_{j+1}=N_{j-1} \text {. }
$$

As a first approximation in a limiting process for evaluation of the virial coefficients it is assumed as a first trial that in the region of this investigation the expansion for the compressiblity factor can be truncated to:

$$
Z=\left(1+B / \bar{V}+C / \bar{V}^{2}\right) .
$$

This expression must be related to the pressure expansion for the compressibility factors since pressure rather than volume is the basic measurement. Equation (3) must be written as:

$$
Z=1+\sum_{n=1}^{\infty} a_{n} P^{n}
$$

Using the general relationship between the coeff-

\footnotetext{
Reference 35, Appendix G. See also, A. E. Hoover and B. W.
} Bicks, Advan. Cryog. Eng. 11, 390 (1966). cient of the pressure and density virial expansions developed by Putnam and Kilpatrick, ${ }^{g 7}$ the expression for $a_{n}$ in terms of the $B$ and $C$ virials of Eq. (3) becomes:

$$
a_{n}=\sum_{k=0}^{k \leq n / 2} \frac{(-1)^{n-k+1}}{(R T)^{n}} \frac{(2 n-k-2) !}{(n-1) !} \frac{B^{n-2 k}}{(n-2 k) !} \frac{C^{k}}{k !} .
$$

Substitution of Eq. (5) into Eq. (1) and rearranging gives

$P_{j}^{2} /\left(P_{j+1} P_{j-1}\right)$

$-\left(1+\sum_{n=1}^{\infty} a_{n} P_{j}^{n}\right)^{2} /\left[\left(1+\sum_{n=1}^{\infty} a_{n} P_{j+1}{ }^{n}\right)\left(1+\sum_{n=1}^{\infty} a_{n} P_{j-1}^{n}\right)\right]=0$.

At constant temperature the coefficients $a_{n}$ are functions of $B$ and $C$ as indicated by Eq. (5).

To start the computation for the coefficients, an approximate value of $C$ was chosen and Eq. (6) was solved for a value of $B$ for each set of three pressures with values of the expansion index $(1,2,3),(2,3,4)$, $(3,4,5)$, etc. Equation (6) was also solved for other combinations such as $j=(1,3,5),(2,4,6),(1,4,7)$, etc. The values of $B$ determined from Eq. (6) were labeled "instantaneous values" and given a subscript equal to the subscript of the central pressure in the group of three pressures used for its evaluation. Using the trial $C$ value and the calculated instantaneous $B$ values, values of $\left(B_{j}+C / \bar{V}_{j}\right)$ were used in a weighted, linear least-squares fit versus values of $1 / \bar{V}_{j}$. For the weighing, errors were considered in the ordinate values, $Y_{j}=$ $\left(B_{j}+C / \bar{V}_{j}\right)$, and in the abscissa values, $X_{j}=1 / \bar{V}_{j}$.

${ }^{37}$ W. E. Putnam and J. E. Kilpatrick, J. Chem. Phys. 21, 1112 (1953). 
HOOVER, NAGATA, LELAND, AND KOBAYASH I

TABLE IV. Values of the experimental third virial coefficients for methane, ethane, and five mixtures in (cc/mole) ${ }^{2}$ and their maximum probable errors (MPE).

\begin{tabular}{|c|c|c|c|c|c|c|}
\hline Gas & $273.15^{\circ} \mathrm{K}$ & MPE & $240.00^{\circ} \mathrm{K}$ & MPE & $215.00^{\circ} \mathrm{K}$ & MPE \\
\hline $\begin{array}{l}\text { Methane } \\
\text { Mixture E } \\
\text { Mixture D } \\
\text { Mixture C } \\
\text { Mixture B } \\
\text { Mixture A } \\
\text { Ethane }\end{array}$ & $\begin{array}{r}2669.6 \\
3945 \\
4972 \\
6562 \\
8036 \\
9265 \\
+11373\end{array}$ & $\begin{array}{l}2 \% \\
6 \% \\
4 \% \\
2 \% \\
3 \% \\
5 \% \\
1 \%\end{array}$ & $\begin{array}{c}3508 \\
5720^{\mathbf{a}} \\
6800 \\
7957 \\
+8891 \\
\cdots \\
-2570\end{array}$ & $\begin{array}{l}3 \% \\
8 \% \\
6 \% \\
8 \% \\
7 \% \\
\because \% \\
4 \%\end{array}$ & $\begin{array}{r}4169 \\
6550 \\
8197^{\mathrm{a}} \\
9886^{\mathrm{a}} \\
+4017^{\mathrm{a}} \\
-1.0 \\
-71100^{\mathrm{a}}\end{array}$ & $\begin{array}{r}4 \% \\
6 \% \\
6 \% \\
10 \% \\
40 \% \\
\ldots \% \\
10 \%\end{array}$ \\
\hline Gas & $200.00^{\circ} \mathrm{K}$ & MPE & $191.06^{\circ} \mathrm{K}$ & MPE & $131.93^{\circ} \mathrm{K}$ & MPE \\
\hline Methane & 4351 & $10 \%$ & +4741 & $10 \%$ & $-13600^{a}$ & $90 \%$ \\
\hline
\end{tabular}

"These six values were calculated by using the appararus constant method. All other values were calculated by using the direct method.

These error weights were given by

$$
w_{j}=\left[\left(\delta Y_{j}\right)^{2}-2 C\left(\delta Y_{j}\right)\left(\delta X_{j}\right)+C^{2}\left(\delta X_{j}\right)^{2}\right]^{-1} .
$$

The straight line selected was the one which minimized the value of:

$$
\sum_{j} w_{j}\left(Y_{j}-B-C x_{j}\right)^{2}
$$

where $w_{j}$ is given by Eq. (7). The values of $\left(\delta X_{j}\right)$ and $\left(\delta Y_{j}\right)$ are

$$
\begin{aligned}
\left(\delta X_{j}\right)^{2} & =\left(\frac{1}{R T}\right)^{2}\left(\left(1+\sum_{n=1}^{\infty} a_{n} P_{j}^{n}\right)^{-1}\right. \\
\left.\times\left\{1-\left[\sum_{n=1}^{\infty} a_{n} n P_{j}^{n}\right] /\left(1+\sum_{n=1}^{\infty} a_{n} P_{j}^{n}\right)\right\}\right)^{2}\left(\delta P_{j}\right)^{2}, & \\
\left(\delta Y_{j}\right)^{2} & =(R T)^{2}\left[\left(1+\sum_{n=1}^{\infty} a_{n} P_{j}^{n}\right)\left(\sum_{n=1}^{\infty} a_{n}(2 n-1) P_{j}^{n-2}\right)\right. \\
& \left.-\sum_{n=1}^{\infty} a_{n} n P_{j}^{n-2}\right]^{2}\left(\delta P_{j}\right)^{2} .
\end{aligned}
$$

The value of $\left(\delta P_{j}\right)$ was calculated from an estimate of $0.01 \%$ as the random error in pressures obtained from the dead-weight gage. The $a_{n}$ coefficients are given by $\mathrm{Eq}$. (5). This procedure is essentially that outlined by Hoover et al..$^{12}$ except that the cross correlation term $2 C\left(\delta Y_{j}\right)\left(\delta X_{j}\right)$ has been introduced in Eq. (7). This term should be included, although its omission apparently does not appreciably effect the final results obtained for $B$ and $C$. The original discussion $^{12}$ also contained some misprints in the equations given for $\left(\delta X_{j}\right)^{2}$ and $\left(\delta Y_{j}\right)^{2}$. Equations (9) and (10) are correct.

The final step in the direct method is to use the slope of the $\left(B_{j}+C / \bar{V}_{j}\right)$ versus $1 / \bar{V}_{j}$ fit to give a better value of $C$. The intercept is the value of $B$ : Iterations were carried out using this sequence of steps until the difference in successive $B$ values changed by less than $0.001 \%$ of the new value for $B$. The criterion used to terminate the series $\sum_{n} a_{n} P^{n}$ was that $\left(Z_{n}-Z_{n-1}\right) / Z_{n}$ be less than or equal to $10^{-6}$. Example applications of the direct method may be found elsewhere. ${ }^{12}$

\section{COMPARISON OF THE APPARATUS CONSTANT METHOD AND THE DIRECT METHOD}

\begin{tabular}{|c|c|c|c|c|c|}
\hline \multirow[b]{3}{*}{$T\left({ }^{\circ} \mathrm{K}\right)$} & \multirow{3}{*}{$\begin{array}{l}B(\operatorname{exptl}) \\
(\mathrm{cc} / \mathrm{mole})\end{array}$} & \multicolumn{4}{|c|}{$B(\operatorname{exptI}-\mathrm{calc})(\mathrm{cc} / \mathrm{mole})$} \\
\hline & & \multicolumn{2}{|c|}{ Kihara } & \multirow[b]{2}{*}{ I-J } & \multirow[b]{2}{*}{ SW } \\
\hline & & I & II & & \\
\hline 191.06 & $-116.31^{\mathrm{a}}$ & -1.68 & -0.09 & -2.60 & -0.20 \\
\hline 200.00 & $-106.68^{a}$ & -1.96 & 0.40 & -2.27 & -0.78 \\
\hline 215.00 & $-92.59 \mathrm{a}$ & -2.11 & 0.82 & -1.69 & -1.29 \\
\hline 240.00 & $-72.72^{\mathrm{a}}$ & -0.99 & 0.04 & 0.13 & -0.52 \\
\hline 273.15 & $-53.28^{\mathrm{a}}$ & +0.08 & -0.71 & 1.58 & +0.33 \\
\hline 273.16 & $-53.35^{b}$ & 0.00 & -0.64 & 1.51 & 0.26 \\
\hline 298.153 & $-42.82^{\mathrm{b}}$ & -0.05 & -0.42 & 1.54 & 0.15 \\
\hline 303.152 & $-40.91^{b}$ & 0.00 & -0.44 & 1.59 & 0.20 \\
\hline 323.151 & $-34.23^{\mathrm{b}}$ & -0.08 & -0.25 & 1.50 & 0.12 \\
\hline 348.153 & $-27.06^{\mathrm{b}}$ & -0.06 & -0.16 & 1.46 & 0.15 \\
\hline 373.160 & $-21.00^{\mathrm{b}}$ & -0.02 & -0.11 & 1.42 & 0.20 \\
\hline 398.170 & $-15.87^{\mathrm{b}}$ & -0.03 & -0.03 & 1.32 & 0.21 \\
\hline 423.183 & $-11.40^{\mathrm{b}}$ & +0.01 & -0.00 & 1.26 & 0.27 \\
\hline 448.197 & $-7.56 \mathrm{~b}$ & -0.01 & 0.07 & 1.14 & 0.27 \\
\hline 473.213 & $-4.16^{\mathrm{b}}$ & +0.01 & 0.10 & 1.06 & 0.29 \\
\hline 498.229 & $-1.16^{\mathrm{b}}$ & +0.02 & 0.13 & 0.98 & 0.30 \\
\hline 523.245 & $1.49 \mathrm{~b}$ & 0.00 & 0.17 & 0.88 & 0.29 \\
\hline 548.260 & $3.89^{\mathrm{b}}$ & 0.02 & 0.19 & 0.82 & 0.30 \\
\hline 573.274 & $5.98^{\mathrm{b}}$ & 0.03 & 0.27 & 0.70 & 0.23 \\
\hline 598.285 & $7.88^{\mathrm{b}}$ & -0.06 & 0.33 & 0.59 & 0.18 \\
\hline 623.294 & $9.66^{\mathrm{b}}$ & -0.04 & 0.33 & 0.55 & 0.18 \\
\hline $\mathrm{rms}$ & & 0.76 & 0.35 & 1.38 & 0.41 \\
\hline $\begin{array}{r}\text { Kihara } I^{c} \\
I I^{8}\end{array}$ & $\begin{array}{l}\epsilon / k=204.3^{\circ} \mathrm{K} \\
\epsilon / k=207.5^{\circ} \mathrm{K}\end{array}$ & \multicolumn{2}{|c|}{$\begin{array}{l}\sigma=3.620 \AA \\
\sigma=3.633 \AA\end{array}$} & $\begin{array}{l}a^{*}=0.2 \\
a^{*}=0.2138\end{array}$ & \\
\hline LrJ & $\epsilon / k=151.4^{\circ} \mathrm{K}$ & \multicolumn{2}{|c|}{$\sigma=3.776 \AA$} & \multirow[b]{2}{*}{$R=1.6^{\mathrm{a}}$} & \\
\hline SW & $\epsilon / k=143.2^{\circ} \mathrm{K}$ & \multicolumn{2}{|c|}{$\sigma=3.346 \AA$} & & \\
\hline
\end{tabular}

Other than the usual assumptions of constant temperature, absence of leaks, complete evacuation, etc., the major assumptions of the direct method as applied

TABLE V. Comparison of calculated and experimental second virial coefficients for methane.

a This work.

b Michels work.

Reference 45. 
VIRIAL COEFFICIENTS OF METHANE AND ETHANE

TABLE VI. Comparison of calculated and experimental second virial coefficients for ethane.

\begin{tabular}{|c|c|c|c|c|c|c|c|c|}
\hline & & \multirow{3}{*}{$\begin{array}{l}B \text { (exptl) } \\
\text { (cc/mole) }\end{array}$} & \multicolumn{6}{|c|}{$B$ (exptl-calc) (cc/mole) } \\
\hline & & & & & Kihara & & & \\
\hline \multicolumn{2}{|c|}{$T\left({ }^{\circ} \mathrm{K}\right)$} & & 1 & 2 & 3 & 4 & L-J & SW \\
\hline \multicolumn{2}{|c|}{$\begin{array}{l}215.00 \\
240.00 \\
273.15 \\
273.15 \\
298.138 \\
322.748 \\
347.652 \\
372.522 \\
397.844 \\
422.700 \\
\text { rms }\end{array}$} & $\begin{array}{l}-340.6^{\mathrm{a}} \\
-276.5^{\mathrm{a}} \\
-223.4^{\mathrm{a}} \\
-221.45^{\mathrm{b}} \\
-185.60^{\mathrm{b}} \\
-156.92^{\mathrm{b}} \\
-133.28^{\mathrm{b}} \\
-114.06^{\mathrm{b}} \\
-97.72^{\mathrm{b}} \\
-83.91^{\mathrm{b}}\end{array}$ & $\begin{array}{r}+5.64 \\
2.66 \\
-6.60 \\
-4.64 \\
-3.23 \\
-1.48 \\
0.01 \\
0.92 \\
1.62 \\
2.37 \\
3.55\end{array}$ & $\begin{array}{r}+2.92 \\
2.69 \\
-5.30 \\
-3.35 \\
-1.82 \\
-0.28 \\
+0.82 \\
1.29 \\
1.49 \\
1.75 \\
2.57\end{array}$ & $\begin{array}{r}+28.65 \\
14.12 \\
-3.95 \\
-2.00 \\
-4.63 \\
-5.61 \\
-6.09 \\
-6.58 \\
-6.95 \\
-6.98 \\
11.27\end{array}$ & $\begin{array}{r}+35.58 \\
+17.71 \\
-3.04 \\
-1.08 \\
-5.00 \\
-6.90 \\
-8.07 \\
-9.09 \\
-9.87 \\
-10.23 \\
14.19\end{array}$ & $\begin{array}{r}-0.25 \\
+3.15 \\
-3.41 \\
-1.46 \\
-0.05 \\
+0.91 \\
1.18 \\
0.72 \\
-0.05 \\
-0.72 \\
1.64\end{array}$ & $\begin{array}{r}+4.24 \\
1.72 \\
-7.19 \\
-5.23 \\
-3.59 \\
-1.63 \\
0.07 \\
1.20 \\
2.10 \\
3.06 \\
3.61\end{array}$ \\
\hline \multirow[t]{4}{*}{ Kihara } & \multicolumn{2}{|c|}{1 sphere } & \multicolumn{2}{|c|}{$\epsilon / k=352.0^{\circ} \mathrm{K}$} & $\sigma=4.116 \AA$ & \multicolumn{2}{|l|}{$a^{k}=0.265$} & \\
\hline & \multicolumn{2}{|c|}{2 line } & \multicolumn{2}{|c|}{$\begin{aligned} \epsilon / k & =297.5^{\circ} \mathrm{K} \\
M & =4.84\end{aligned}$} & $\begin{aligned} \rho_{0} & =4.126 \AA \AA \\
S & =0\end{aligned}$ & \multicolumn{2}{|l|}{$\begin{array}{l}l=1.54 \AA \\
V=0\end{array}$} & \\
\hline & \multicolumn{2}{|c|}{3 triangular prism } & \multicolumn{2}{|c|}{$\begin{aligned} \epsilon / k & =410.0^{\circ} \mathrm{K} \\
M & =10.17\end{aligned}$} & $\begin{aligned} \rho_{0} & =3.050 \AA \\
S & =5.77\end{aligned}$ & \multicolumn{2}{|l|}{$V=0.653$} & \\
\hline & \multicolumn{2}{|c|}{4 circular cylinder } & \multicolumn{2}{|c|}{$\begin{aligned} \epsilon / k & =420.0^{\circ} \mathrm{K} \\
M & =11.04\end{aligned}$} & $\begin{aligned} \rho_{0} & =2.958 \AA \\
S & =7.793\end{aligned}$ & \multicolumn{2}{|l|}{$V=1.576$} & \\
\hline \multicolumn{3}{|l|}{$\mathrm{L}-\mathrm{J}$} & \multicolumn{2}{|c|}{$\epsilon / k=202.0^{\circ} \mathrm{K}$} & $\sigma=4.912 \AA$ & & & \\
\hline \multicolumn{3}{|l|}{ SW } & \multicolumn{2}{|c|}{$\epsilon / k=232.0^{\circ} \mathrm{K}$} & $\sigma=3.791 \AA$ & $R=1.60$ & & \\
\hline
\end{tabular}

b Michels et al. (Ref. 34).

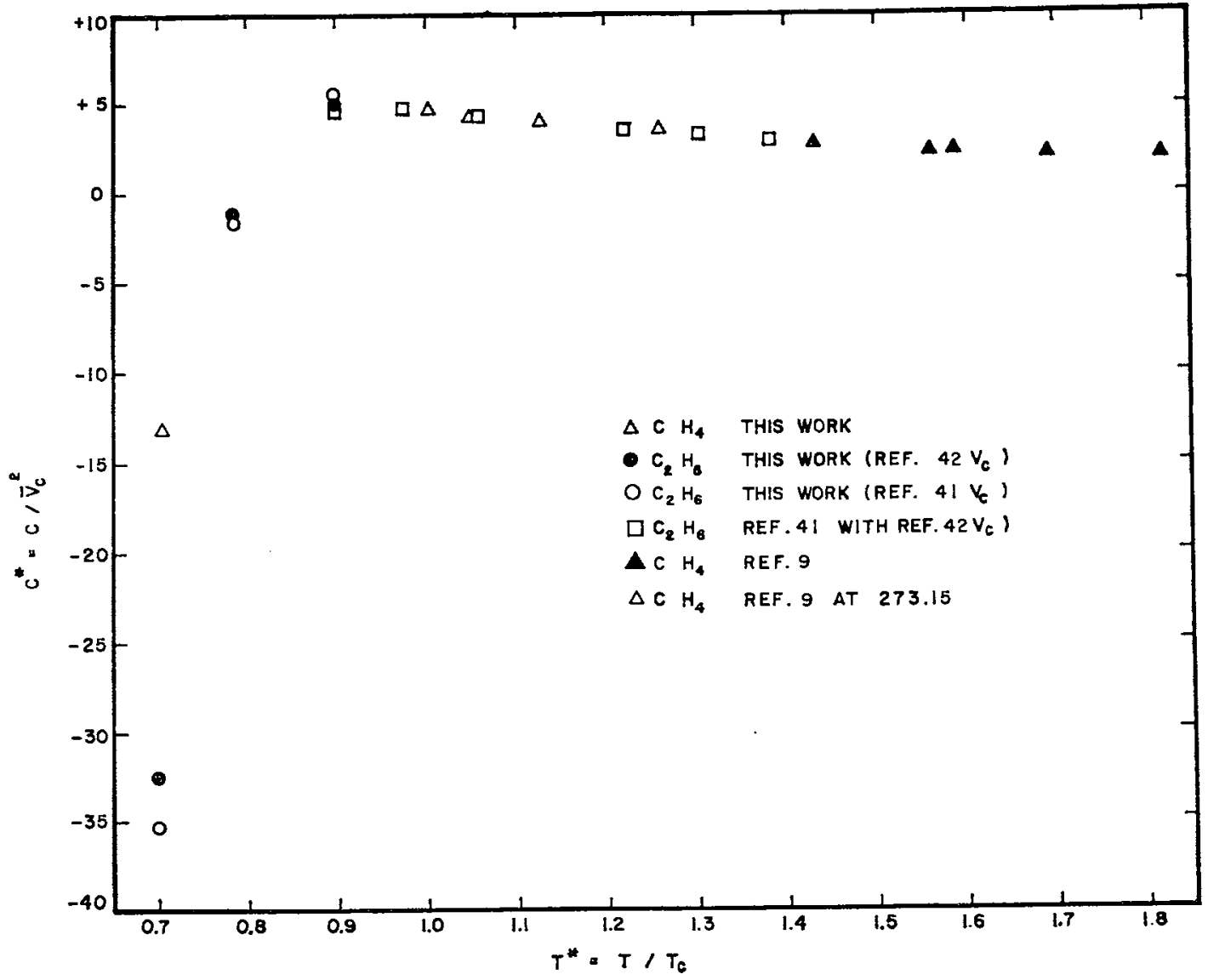

FIG. 9. Reduced third virial coefficients. 
TABLE VII. Comparison of calculated and experimental $B_{12}$ for methane-ethane mixture.

\begin{tabular}{|c|c|c|c|c|}
\hline Temp $\left({ }^{\circ} \mathrm{K}\right)$ & & 215 & 240 & 273.15 \\
\hline $\begin{array}{l}\text { Experimental } \\
\mathrm{cc} / \mathrm{mole}\end{array}$ & & -192.29 & -158.17 & -111.86 \\
\hline \multicolumn{5}{|l|}{$\begin{array}{l}\text { Calculated } \\
\text { cc/mole }\end{array}$} \\
\hline Kihara & $\begin{array}{l}1 \\
2 \\
3 \\
4\end{array}$ & $\begin{array}{l}-177.74 \\
-178.89 \\
-179.34 \\
-182.12\end{array}$ & $\begin{array}{l}-143.27 \\
-145.26 \\
-144.49 \\
-147.00\end{array}$ & $\begin{array}{l}-110.21 \\
-111.78 \\
-111.09 \\
-113.08\end{array}$ \\
\hline L-J & & -181.69 & -147.88 & -114.39 \\
\hline SW & & -179.56 & -144.53 & -111.12 \\
\hline
\end{tabular}

1, sphere for methane (Ref. 45) and sphere for ethane (this work) 2, sphere for methane (Ref. 45) and line for ethane (this work); 3, sphere for both methane and ethane (this work); 4 , sphere for methane and line for ethane (this work)

in this work are:

(1) the apparatus constant $N_{j}$ is independent of pressure between adjacent expansions, and

(2) the truncated form of the virial expansion in Eq. (3) is valid.

For the pressure range of this study (1-40 atm) it has been shown ${ }^{35}$ that assumption (1) introduces negligible error. It is necessary to use data obtained in a density range in which assumption (2) does not introduce excessive errors in the determination of $B$ and $C$. This assumption may be tested by excluding the highest pressure, recalculating $B$ and $C$, and comparing the values obtained by including the highest pressure.

Some advantages of the direct method over the apparatus constant method are:

(1) the helium calibration to obtain the cell constant $N_{\infty}$ with high precision $( \pm 0.001 \%)$ is not required,

(2) the elimination of the determination of the ratio $P_{0} / Z_{0}$ at high pressures, ${ }^{12}$ and

(3) the minimization of systematic error in the piston area uncertainties due to the nature of $\mathrm{Eq}$. (6). The over-all result is that advantages (1) through (3) can permit an improved evaluation of $B$.

Some disadvantages of the direct method are:

(1) the need for an initial estimate of $B$ and $C$ for the iterative solution for their true values, and

(2) the need for a large number of pressure measurements during the expansion, limiting the method to $T_{R}>0.75$ for present pressure measuring equipment.

In this study, initial estimates of $B$ were obtained from Refs. 30 and 31; and for $C$ from Ref, 38. ${ }^{38}$ J. O. Hirschelder, C. F. Curtiss, and R. B. Bird, Molecular
Theory of Gases and Liquids (John Wiley \& Sons, Inc., New York, 1954).

\section{SUMMARY OF ERROR ANALYSIS}

The detailed account of the error analysis is reported elsewhere $^{35}$ and only the important conclusions are outlined here.

The kinds of errors discussed in the following section are:

(1) errors in the primary temperature and pressure measurements,

(2) errors in the impurities and analyses of the gases,

(3) errors due to discrepancies between the experimental procedures and the analytical expressions representing the Burnett procedure as, for example, errors due to incomplete evacuation, failure to reach thermal equilibrium after each expansion, etc.,

(4) errors propagated directly to the virial coefficients through the direct method, and

(5) errors propagated to the compressibility factor and thence to the virial coefficients when using the apparatus constant method.

The temperature control and measurement of the cell $\left( \pm 0.0005^{\circ} \mathrm{C}\right.$ with knowledge of absolute temperature to $\pm 0.01^{\circ} \mathrm{K}$ ) was such that it could be shown that the temperature control contributed negligibly to the error in the pressure measurement $( \pm 0.02 \%)$ and, therefore, negligibly to the compressibility factors and the virial coefficients.

The use of the gas-lubricated piston gage with the DPC zero shift measured after each pressure measurement leaves the uncertainty in the knowledge of the piston area as the major error. This uncertainty along with other minor errors is sufficient to cause a

TABLE VIII. Comparison of calculated and experimental third virial coefficients for methane.

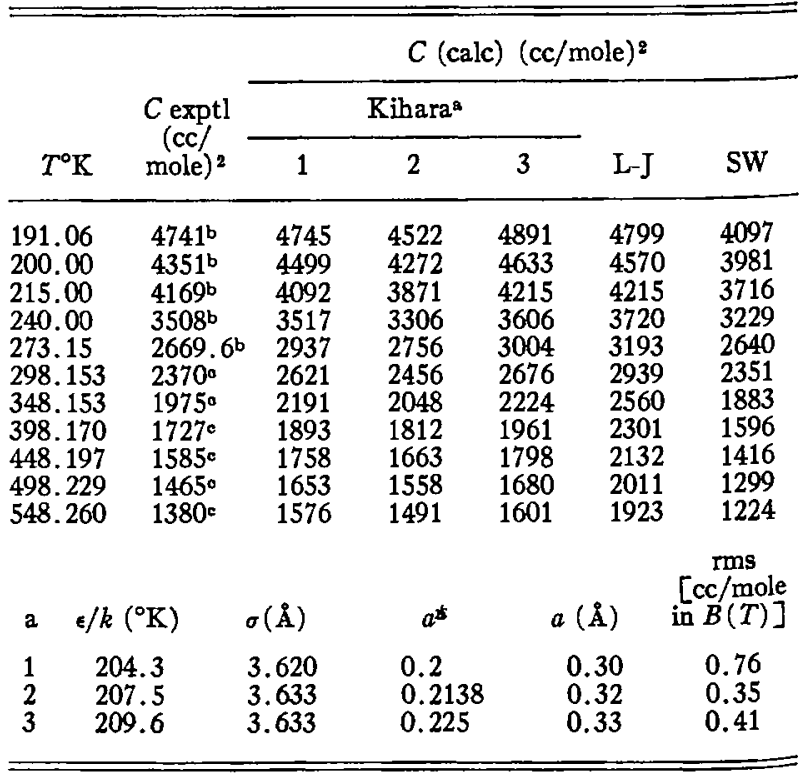

a Kihara.

b This work.

- Douslin (Ref. 9). 
maximum error of $0.015 \%$ and $0.0097 \%$ for pressures measured using the high- and low-range pistons, respectively.

The 0.01 mole $\%$ impurity in the pure ethane caused negligible contributions to the measured virial coefficients for ethane. The second virial coefficient of methane containing $0.03 \% \quad \mathrm{CO}_{2}$ and $0.2 \% \quad \mathrm{~N}_{2}$ at $273.15^{\circ} \mathrm{K}$ was determined as $-53.29 \mathrm{cc} /$ mole whereas this value corrected to pure methane is estimated to be $-53.36 \mathrm{cc} / \mathrm{mole}$. The corrected and uncorrected second virial coefficients for gas from this work and from other sources are reported in Table II. At lower temperatures the second virial coefficients for methane are not corrected for trace gases because the most probable error is greater than the small correction due to these impurities. The most probable error in the third virial coefficients are such that the contribution of the trace impurities is quite negligible. A similar statement holds true for any interaction virial computations.

The basic equation used in the direct method is Eq. (1). Examination of Eq. (1) shows that it is not a function of the piston area, hence there is no error due to uncertainty in the value of this area.

The "instantaneous value" of $B_{j}$ depends upon the three pressures appearing in Eq. (1) :

$$
B_{j}=B_{j}\left(P_{j+1}, P_{j}, P_{j-1}\right) \text {. }
$$

Also, for the low to moderate pressure region and for purposes of this error analysis, one may write:

$$
Z_{j}=Z_{j}\left(B_{j}, P_{j}\right) \text {. }
$$

Differentiating $B_{j}$ implicitly gives relations for the differentials $\partial B_{j} / \partial P_{j_{ \pm 1}}$ and $\partial B_{j} / \partial P_{j}$ as follows:

$$
\begin{aligned}
\frac{\partial B_{j}}{\partial P_{j \pm 1}} & =\frac{\left(1 / P_{j \pm 1}\right)-\left(\partial Z_{j \pm 1} / \partial P_{j \pm 1}\right) Z_{j \pm 1}{ }^{-1}}{\left(\partial Z_{j+1} / \partial B_{j}\right) Z_{j+1}^{-1}+\left(\partial Z_{j-1} / \partial B_{j}\right) Z_{j-1}{ }^{-1}-2\left(\partial Z_{j} / \partial B_{j}\right) Z_{j}^{-1}} \\
\frac{\partial B_{j}}{\partial P_{j}} & =\frac{-2\left[\left(1 / P_{j}\right)-\left(\partial Z_{j} / \partial P_{j}\right) / Z_{j}\right]}{\left(\partial Z_{j+1} / \partial B_{j}\right) Z_{j+1}{ }^{-1}+\left(\partial Z_{j-1} / \partial B_{j}\right) Z_{j-1}^{-1}-2\left(\partial Z_{j} / \partial B_{j}\right) Z_{j}^{-1}}
\end{aligned}
$$

It is noted that $\partial B_{j} / \partial P_{j}$ is opposite in sign from the errors $\partial B_{j} / \partial P_{j+1}$ and $\partial B_{j} / \partial P_{j-1}$. This means that given an error in $P_{j}$, the value of $\left(B_{k}+C / \bar{V}_{k}\right)$ plotted versus $1 / \tilde{V}_{k}$ for $k=j+1, j$, and $j-1$ will fall in the sequence high-low-high or low-high-low. Therefore, part of the effect of random errors cancels. Should pressures adjacent to $P_{j}$ contain errors, the situation becomes more complicated. Equations (13) and (14) may be applied to study the actual magnitudes of $\partial B_{j} / \partial P_{j}$ or of $\partial B_{j} / \partial P_{j \pm 1}$.

Before studying the effect of random pressure errors on the errors in the second virial coefficients it is advantageous to render Eq. (14) dimensionless by multiplying $\partial B_{j} / \partial P_{j}$ by $P_{j} / B_{j}$. This product plotted versus $Z_{j}$ is shown in Fig. 2 .

For a given apparatus constant $N_{\infty}$ and a given sequence of points, the plot of $\left[-\left(P_{j} / B_{j}\right)\left(\partial B_{j} / \partial P_{j}\right)\right]$ versus $Z_{j}$ is seen to give a single function for all gas compositions studied. Two significant features shown in Fig. 2 are: (1) for a given $N_{\infty}$ a given error in the pressure measurement results in a correspondingly greater error in the second virial coefficient; and (2) as one decreases $N_{\infty}$ to obtain the requisite number of expansions, for example, in the region below the critical temperature, the relative error in $B_{j}$ increases. Thus, it was found that to maintain a relative precision in $B_{j}$ better than $1.0 \%$ it was necessary to work at temperatures equal to or greater than $0.75 T_{c}$ for a pure gas. Higher values of $N_{\infty}$ generally give smaller errors.
With the direct method there is a way to lower the relative errors in $B_{j}$ for data taken at a particular apparatus constant value. This is done by solving the basic relation, Eq. (6), for many different groupings of the three pressure expansions. For example, the equation may be solved for the sequence of values of $j=$ $(1,3,5),(2,4,6), \cdots$, etc. combined also with the sequence $j=(1,2,3),(2,3,4), \cdots$, etc., and all other possible combinations of $(j-k, j, j+k)$ where $k$ takes on integral values equal to or greater than one. This procedure effectively raises the single sequence value of $N_{\infty}$ to a power equal to the number of overlapping sequences. This effective value of $N_{\infty}$ is not needed in the direct calculation itself, but its value does affect the errors in the method produced by errors in measured pressures. The relative lowering of the error in $B_{j}$ is shown in Fig. 2. The curve using two overlapping sequences with $k=1$ and $k=2$ is labeled $N_{\infty}{ }^{2}=(1.16)^{2}=$ 1.34. The single sequence using only $k=1$ is shown with $N_{\infty}=1.16$ and has a significantly larger error function. The curve for $N_{\infty}=1.58$ was determined by actually changing the volume ratio of the chambers.

Calculations show that with the direct method a systematic error in the pressure of $0.01 \%$ would cause an error of about $0.013 \%$ in $B$ and $0.04 \%$ in $C .{ }^{35}$ This error is cumulative in the $Z_{j}$ values in the apparatus constant method.

Evaluations of the errors to the compressibility factor and thence to the virial coefficients were made following the procedure developed by Canfield et al..$^{11}$ 
TABLE IX. Comparison of calculated and experimental third virial coefficients for ethane.

\begin{tabular}{lrrrr}
\hline & & \multicolumn{3}{c}{$\begin{array}{c}C \text { (calc) } \\
(\mathrm{cc} / \mathrm{mole})^{2}\end{array}$} \\
\cline { 4 - 6 }$T\left({ }^{\circ} \mathrm{K}\right)$ & $\begin{array}{c}C \text { exptl } \\
(\mathrm{cc} / \mathrm{mole})^{2}\end{array}$ & Kihara & $\mathrm{L}-\mathrm{J}$ & $\mathrm{SW}$ \\
\cline { 4 - 6 } 215.00 & -71099 & 8410 & 23332 & -5370 \\
240.00 & -2570 & 12985 & 22132 & 5372 \\
273.15 & 11373 & 13261 & 19692 & 9253 \\
273.15 & 10607 & 13261 & 19692 & 9253 \\
298.138 & 10737 & 12208 & 17954 & 9531 \\
322.748 & 9671 & 11012 & 16478 & 9082 \\
347.652 & 8576 & 9874 & 15217 & 8393 \\
372.522 & 7709 & 8882 & 14171 & 7673 \\
397.844 & 7001 & 8035 & 13287 & 6980 \\
422.700 & 6375 & 7318 & 12629 & 6370 \\
\hline \hline
\end{tabular}

The analysis showed that at low reduced temperatures, e.g., below 0.85 , the generally less accurate apparatus constant method is preferred to the direct method because of the limitation on the number of expansions imposed by the two-phase boundary of the system and the minimum pressure which the apparatus can measure.

\section{DISCUSSION OF EXPERIMENTAL RESULTS}

In this section the values of the virial coefficients are compared with similar results of other investigators. Different tests are presented which show the limits of the self-consistency of the data of this work. The second virial coefficients are compared with two recently published correlations.

The empirical correlation by McGlashan and Potter ${ }^{30}$ is based on data taken at reduced temperatures as low as 0.5 and as high as 6.0 for the first eight hydrocarbons. It also agrees well with the published data for argon, krypton, and xenon. The Pitzer and Curl ${ }^{31}$ correlation uses Pitzer's acentric factor as a parameter. It was based on data for a wider variety of gases. Gases with as much structural difference as benzene and argon are included. The data, however, are at reduced temperatures greater than 1.1. The data in this work fall between $T_{R}$ values of 0.7 and 1.4.

Finally, the force parameters for several potential functions are presented and compared with similar values of these parameters found in the literature.

\section{A. Comparison and Discussion of Second Virial Coefficients}

\section{Internal Consistency of the Second Virial Coefficients of this Work}

In Fig. 3 the experimental second virial coefficients of this work at $273.15^{\circ}, 240.00^{\circ}$ and $215.00^{\circ} \mathrm{K}$ versus mole fraction ethane are presented.
Since at constant temperature

$$
B_{m}=\sum_{i} \sum_{j} x_{i} x_{j} B_{i j}
$$

the mixture second virials, $B_{m}$, can be expressed as a second order polynomial in the mole fraction of ethane. The standard deviation of the ordinate values is then a good measure of the internal consistency of the data. These calculations were made and the curves were drawn as shown in Fig. 3 and tabulated in Table III along with tabulations of the maximum probable experimental errors. The values of relative standard deviations are $0.25 \%$ at $273.15^{\circ} \mathrm{K}, 0.6 \%$ at $240.00^{\circ} \mathrm{K}$, and $1.6 \%$ at $215.00^{\circ} \mathrm{K}$. Unfortunately there are no other second order virial data on methane-ethane mixtures available for comparison.

In Fig. 4 the values of $B$ measured in this work versus temperature at constant composition are presented.

\section{Comparison of $B_{\mathrm{CH}_{4}}$ and $\mathrm{B}_{\mathrm{C}_{2} \mathrm{H}_{6}}$ with Similar Values from Other Investigators}

At $0^{\circ} \mathrm{C}$ several investigators have measured the second virial coefficients of pure $\mathrm{CH}_{4}$ and pure $\mathrm{C}_{2} \mathrm{H}_{6}$. Several of the values for $B_{\mathrm{CH}_{4}}$ were all so close together that they appear as a single point in Fig. 5. The values of $B_{\mathrm{CH}_{4}}$ and $B_{\mathrm{C}_{2} \mathrm{H}_{6}}$ are compared in Tables $\mathrm{V}$ and VI.

Saville ${ }^{32}$ has recently evaluated the values of $B_{\mathrm{CH}_{4}}$ from measurements by Michels et al., ${ }^{27}$ Schamp et al. ${ }^{25}$ Kvalnes and Gaddy, ${ }^{26}$ Olds et $a l .,^{40}$ and Thomaes and van Steenwinkel. ${ }^{2}$ Saville ${ }^{39}$ recommends $-53.44 \pm 0.06$ $\mathrm{cc} / \mathrm{mole}$ for the value of $B_{\mathrm{CH}_{4}}$ at $273.15^{\circ} \mathrm{K}$. The value of $-53.36 \mathrm{cc} / \mathrm{mole}$ reported for this work in Table II is equal to the calculated value -53.28 plus the correction for the $\mathrm{CO}_{2}$ and $\mathrm{N}_{2}$ mentioned. Michels' ${ }^{27}$ methane contained about $0.2 \%$ ethane and a corrected value calculated by this author is also presented in Table II. The value of $B_{\mathrm{CH}_{4}}$ due to Schamp et al. ${ }^{25}$ was given the greatest weight in Saville's evaluation. The accuracy of Douslin's measurement was reported as 0.07 to $0.10 \mathrm{cc} / \mathrm{mole}$. The precision of the measurement of this present work was $0.002 \mathrm{cc} /$ mole for $B_{\mathrm{CH}_{4}}$ at $0^{\circ} \mathrm{C}$. This precision is the standard deviation computed for the intercept, $B$, of the equivalent of $B_{j}+C / \bar{V}_{j}$ versus $1 / \bar{V}_{j}$ when the direct method of calculation was used. The accuracy of the value of $B_{\mathrm{CH}_{4}}$ corrected for $\mathrm{CO}_{2}$ and $\mathrm{N}_{2}$ impurities is about $0.03 \mathrm{cc} /$ mole. McGlashanPotter ${ }^{30}$ curves for $\mathrm{CH}_{4}$ and $\mathrm{C}_{2} \mathrm{H}_{6}$ are shown in Figs. 5 and 6 , respectively. Pitzer and Curl's ${ }^{31}$ correlation is also shown for $\mathrm{CH}_{4}$ and $\mathrm{C}_{2} \mathrm{H}_{6}$ in Figs. 5 and 6 . As shown in Fig. 5, the second virial coefficients at $191.06^{\circ} \mathrm{K}$ and higher temperatures for methane from this work

${ }^{39}$ G. Saville, Ph.D. thesis, University of Oxford, Oxford, England, 1961.

${ }^{40}$ R. H. Olds, H. H. Reamer, B. H. Sage, and W. N. Lacey, Ind. Eng. Chem. 35, 922 (1943). 
are in good to excellent agreement with other published data and the two correlations.

Thomaes and van Steenwinkel ${ }^{2}$ assumed that $(Z=$ $1+B / V)$ because they were operating below one atmosphere. The third virial coefficient at their coldest temperature at $T_{R}=0.57$ is less than -100000 (cc/ mole $)^{2}$ as estimated from Fig. 9. Ignoring this large, negative third virial coefficient at their low temperatures would cause their values of the second virial coefficient to be algebraically low.

Price ${ }^{1}$ reported values of $B_{T^{\circ} \mathrm{C}}=\left(B_{\text {measured }}-B_{0^{\circ} \mathrm{C}}\right)$. Since his value of $B$ at $0^{\circ} \mathrm{C}$ is about $19 \mathrm{cc} / \mathrm{mole}$ too high, all of his reported values are too high.

Mueller et $a l .^{29}$ used a Burnett expansion and the apparatus constant method. A probable error of $1.0 \%$ in the values of $B$ was given; however, this was based on only four expansions for the lowest temperature. Furthermore, helium calibration runs for all of these isotherms were not made.

$\mathrm{K}_{\text {anda }}{ }^{3}$ used an expansion method to first measure $(\partial H / \partial P)_{T}$ at several low pressures and then using only three points extrapolated to zero pressure to find $(\partial H / \partial P)_{T^{0}}$. This was related to the second volume virial coefficient where the assumption $Z=\left(1+B^{\prime} P\right)$ was made. His values of the second virial coefficients are higher than McGlashan and Potter's curve.

For ethane, only Eucken and Parks ${ }^{4}$ have published second virial coefficients below $0^{\circ} \mathrm{C}$. They are noticeably below values calculated using the McGlashan and Potter correlation. However, the value of $V_{c}$, which must be used in this correlation, is uncertain by $4.5 \%$. $\operatorname{Din}^{41}$ reports a value of $141.7 \mathrm{cc} / \mathrm{mole}$ and Rossini ${ }^{42}$ reports a value of 148 . The McGlashan-Potter curves in Fig. 6 are based on the former. The ethane virial coefficients of this present work agree well with the McGlashan-Potter correlation and are higher than the values of Eucken and Parks. Eucken and Parks, like Kanda, measured $(\partial H / \partial P)_{T}$. The assumption that $C^{\prime}=0$, which is required by this method, would cause Eucken and Parks's numbers to be low if the assumption is not completely valid. The corresponding states plot for the second virial coefficients is shown in Fig. 7.

\section{B. Corresponding States Plot of the Third Virial Coefficients of This Work and Other Investigators}

Figure 8 is drawn to show the self-consistency of the third virial coefficients of this work. Table IV presents the experimental values. Only Michels et al..$^{34}$ and Douslin ${ }^{9}$ present values (given in Table II for $0^{\circ} \mathrm{C}$ ) which may be directly compared with those of this work. Figure 9 presents $C / V_{c}{ }^{2}$ versus $T_{B}$ to shown that the

41 F. Din, Thermodynamic Functions of Gases (Butterworths Publications Ltd., London 1961), Vol. 3.

${ }_{42}$ A PI Project 44, F. D. Rossini, Ed. (Carnegie Press, Pittsburgh, Pa., 1953). agreement of the values for methane and ethane with those of others is good at $T_{R}$ values greater than 0.9 . Below the value of $T_{R}=0.8$ no other experimental third virial coefficient data are known to exist for the gases studied.

\section{Virial Coefficients of Methane in This Work at $131.93^{\circ} \mathrm{K}$}

The error index $\left[-P_{j}\left(\partial B_{j} / \partial P_{j}\right)\left(B_{j}\right)^{-1}\right]$ indicates that the direct method is inappropriate for an accurate determination of the virial coefficients at this low temperature. Furthermore, only one helium expansion series was made for evaluation of the apparatus constant. This helium expansion series gives a second virial coefficient for helium which is too high, 13.71 $\mathrm{cc} /$ mole versus a literature value at this temperature of about $11.8 .^{12}$ Using a revised apparatus constant consistent with the 11.8 value for helium gives a methane second virial coefficient of $-224 \mathrm{cc} / \mathrm{mole}$ and a third virial coefficient of $-13600(\mathrm{cc} / \mathrm{mole})^{2}$. Thus, the virial values obtained for methane at $139.13^{\circ} \mathrm{K}$ are not exactly absolute values as the other reported values are but are relative to the experimental second virial coefficient reported for helium at the same temperature.

\section{POTENTLAL FUNCTIONS}

With the new virial coefficient data at low temperatures in the present investigation, the parameters of various potential functions have been redetermined from second virial data over a wider temperature range. Parameters for the Kihara, Lennard-Jones, and square-well potentials have been re-evaluated.

Kihara ${ }^{43}$ proposed a potential between molecules having a characteristic impenetrable core. The interaction potential energy is expressed as a function of the shortest distance $\rho$ between the surfaces of the molecular cores:

$$
U(\rho)=\epsilon\left[\left(\rho_{0} / \rho\right)^{12}-2\left(\rho_{0} / \rho\right)^{\mathfrak{6}}\right],
$$

where $\epsilon$ is the maximum energy of attraction and $\rho_{0}$ is its position. Kihara derived the following expression for the second virial coefficient:

$$
\begin{aligned}
B / N=\frac{2}{3} \pi \rho_{0}^{3} F_{3}+M_{0 \rho_{0}}{ }^{2} F_{2} & +\left[S_{0}+\left(M_{0}^{2} / 4 \pi\right)\right] \\
& \times \rho_{0} F_{1}+\bar{V}_{0}+\left(M_{0} S_{0} / 4 \pi\right),
\end{aligned}
$$

where $M_{0}, S_{0}$, and $\bar{V}_{0}$ can be calculated from the size and shape of the core. $F_{1}, F_{2}$, and $F_{3}$ depend on the reduced temperature $T^{*}=k T / \epsilon$ and are given by

$$
\left.F_{s}=-\frac{s}{12} \sum_{j=0}^{\infty} \frac{2^{j}}{j !} \Gamma\left(\frac{6 j-s}{12}\right) T^{*}-\frac{6 j+s}{12}\right)
$$

In the present investigation the $F$, series was termi-

48 T. Kihara, Rev. Mod. Phys. 25, 831 (1953). $T^{*}-(4 j+5) / 12$ 
nated when the last term became less than $10^{-5}$. For a spherical model the following potential form was used:

$$
\begin{array}{rlrl}
U(r) & =\infty & \gamma \leq 2 a \\
& =4 \epsilon\left[\left(\frac{\sigma-2 a}{\gamma-2 a}\right)^{12}-\left(\frac{\sigma-2 a}{\gamma-2 a}\right)^{6}\right] & \gamma>2 a, \\
a^{*} & =2 a /(\gamma-2 a) & &
\end{array}
$$

where $a$ is the core radius and $\sigma$ is the value of $r$ for $U(r)=0$. The Kihara potential reduces to the LennardJones potential if the core size becomes zero. The square-well potential is the simplest three parameter potential and is given by:

$$
\begin{aligned}
U(r) & =\infty & & \gamma>\sigma \\
& =-\epsilon & & \sigma<\gamma<R \sigma \\
& =0 & & \gamma>R \sigma .
\end{aligned}
$$

$R$ is the ratio of well width to $\sigma$. The second virial coefficient for the square-well potential is

where

$$
\begin{gathered}
B(T)=b_{0}\left[1-\left(R^{3}-1\right)\left(e^{\ell / k T}-1\right)\right], \\
b_{0}=\frac{2}{3} \pi N \sigma^{3} .
\end{gathered}
$$

\section{DETERMINATION OF POTENTIAL PARAMETERS FROM SECOND VIRIAL COEFFICIENT DATA}

Potential parameters were determined by the least square method by minimizing the root-mean-square deviation between calculated and experimental second virial coefficient data. Tables $\mathrm{V}$ and VI show the experimental values and the numerical values of the potential parameters. The agreement between the experimental and calculated second virial coefficients using the Kihara model was in close agreement with previously calculated values. The triangular prism core model of the Kihara potential for the ethane molecule described by Prausnitz and Myers ${ }^{44}$ was used in the present investigation. Calculated values below the ice point showed increasing deviations from the experimental values with decreasing temperature. Another cylindrical core model, which tightly encloses the triangular prism core, yielded even poorer agreement with the experimental data. Of the Kihara core models tested, the line model gave the smallest deviation from the experimental results. It has been generally found that the Kihara potential is superior to the LennardJones potential, especially in the calculation of $B(T)$ for methane, propane, and other normal paraffins. ${ }^{45.46}$ However, it is to be noted that the Lennard-Jones

${ }^{44}$ J. M. Prausnitz and A. L. Myers, A. I. Ch. E. J. 9,5 (1963). 45 A. E. Sherwood and J. M. Prausnitz, J. Chem. Phys. 41, 429 (1964).

${ }_{46} \mathrm{~J}$. F. Connolly and G. A. Kandalic, Phys. Fluids 3, 463 (1960). potential in this study was superior to the Kihara potential in representing $B(T)$ data for ethane.

The second virial coefficient for a mixture is given by Eq. (15).

For the Kihara potential the interaction virial for unlike pairs $B_{12}$ is expressed by:

$$
\begin{aligned}
& B_{12}=\frac{2}{3} \pi \rho_{12}{ }^{3} F_{3}+\frac{1}{2}\left(M_{01}+M_{02}\right) \rho_{12}{ }^{2} F_{2} \\
&+ {\left[\frac{1}{2}\left(S_{01}+S_{02}\right)+\left(M_{01}+M_{02}\right) / 4 \pi\right] \rho_{12} F_{1} } \\
&+\frac{1}{2}\left(\bar{V}_{01}+\bar{V}_{02}\right)+\left(M_{01} S_{01}+M_{02} S_{02}\right) / 8 \pi
\end{aligned}
$$

where $\epsilon_{12}$ and $\rho_{12}$ of the mixture are calculated by

$$
\begin{gathered}
\epsilon_{12}=\left(\epsilon_{1} \epsilon_{2}\right)^{1 / 2}, \\
\rho_{12}=\frac{1}{2}\left(\rho_{11}+\rho_{12}\right) .
\end{gathered}
$$

These empirical combining rules were also used for all other potential functions studied. An equation similar to Eq. (24) was used for $\sigma_{12}$. The numerical values of $B_{12}$ were calculated using the three potential functions. Table VII gives the comparison of experimental values with calculations. For the square-well potential it was assumed that $R_{12}=\left(R_{1}+R_{2}\right) / 2$. Table VII shows that the Kihara, the Lennard-Jones, and the square-well potentials gave $B_{12}$ values close to the experimental values. In the Kihara potential the use of a spherical core for methane and line core for ethane gave slightly better results for $B_{12}$ than those predicted by the application of spherical model for methane and ethane.

\section{THIRD VIRIAL COEFFICIENTS}

Calculated third virial coefficient curves were obtained by using the parameters given in Tables $\mathrm{V}$ and VI from the following relations:

$$
\begin{gathered}
C(T)=b_{0}{ }^{2} C^{*}, \\
C^{*}=C_{\text {add }}{ }^{*}+\Delta C^{*}, \\
\Delta C^{*}=\alpha^{*}\left(\partial \Delta C^{*} / \partial \alpha^{*}\right)_{\alpha^{*}=0,}
\end{gathered}
$$

where reduced polarizability is given by $\alpha^{*}=\alpha / \sigma^{3}$ and the average polarizabilities of methane and ethane are 2.60 and $4.47 \AA^{3}$, respectively. 47

The reduced additive coefficients $C_{\text {add }}{ }^{*}$ and the nonadditive derivative $\partial \Delta C^{*} / \partial \alpha^{*}$ are tabulated by Sherwood and Prausnitz. ${ }^{48}$ The additive square-well third virial coefficients were calculated by using an analytical equation by Kihara. ${ }^{38}$ Table VIII shows a comparison of calculated and experimental results for methane at several temperatures. This tabie includes the results calculated using the Kihara potentials with different spherical core sizes. The choice of core

${ }^{47} H$. H. Landolt-Börnstein, Zahlenwerte und Funktionen (Springer-Verlag, Berlin, 1951), Vol. 1, pt. 3, p. 509.

${ }^{48}$ Sherwood and Prausnitz, J. Chem. Phys. 41, 413. (1964). 
radius of $0.32 \AA$ for methane yielded about $95 \%$ of the calculated third virial coefficients when the core radius was chosen as $0.30 \AA$. Table $\Gamma X$ gives the calculated and experimental values of $C(T)$ for ethane. The Lennard-Jones potential gave the highest calculated $C(T)$ values and the square-well potential the lowest. The calculated values using the Kihara potential fell between those from the Lennard-Jones and those from the square-well potential. The square-well potential did very well for the two substances investigated here in spite of its simple form.

\section{ACKNOWLEDGMENTS}

The author thanks the Phillips Petroleum Company, the Associated Oil and Gas Company, and the Tennessee Gas Transmission Company for their generous supply of materials; Monsanto Chemical Company and Shell Oil Company for mass-spectrographic analyses; The National Science Foundation and the Sun Oil Company for financial support of Hoover; and NASA for Grant NsG-6-59 for the financial support of Professor Isamu Nagata. 